\title{
Hacia un ñandereko latinoamericano: identidad de resistencia e integración contrahegemónica
}

\author{
Félix Pablo Friggeri*
}

\section{ReSUMEN}

En este trabajo se problematiza la integración latinoamericana desde la articulación de las luchas populares contrahegemónicas y desde la construcción de identidades de resistencia al avance del capitalismo neoliberal enraizadas en las tradiciones antiimperialistas. Se destaca cómo la dimensión contrahegemónica ha estado presente cada vez que hubo avances reales en este proceso de integración. Se analiza el papel y las posibilidades que las luchas populares tienen en el mismo y cuáles son los espacios de construcción de estas articulaciones y búsquedas identitarias. También cómo este proceso de integración desde abajo, desde los pueblos, desde las organizaciones populares, puede aportar a repensar la llamada Teoría de las Relaciones Internacionales desde América Latina en un enfoque descolonizador epistémico-político. Se propone el concepto de ñandereko latinoamericano, partiendo de la idea guarani de una identidad contrastiva, intercomunitaria que afirma una vida en comunidad igualitaria entre los hombres y en profunda relación con la naturaleza, como fuente de inspiración en la construcción de identidades de resistencia y unión latinoamericanas.

\section{Palabras clave}

América Latina; integración contrahegemónica; identidad; resistencia; ñandereko latinoamericano.

\section{*Félix Pablo} FRIGGERI ,

Doctor, Profesor Adjunto en el Área de Relaciones Internacionales e Integración en la Universidad Federal de la Integración Latinoamericana; Director del Instituto de Economía, Sociedad y Política en la Universidad Federal de la Integración Latinoamericana.

\section{Recibido:}

16/03/2018

Aceptado:

01/10/2018

DOI:

TiTLE

Towards a Latin American Ñandereko:identity of Resistance and anti-hegemonic integration

\section{Abstract}

In this work we problematizes Latin American integration from the articulation of the counterhegemonic popular struggles and from the construction of identities of resistance to the advancement of neoliberal capitalism rooted in the traditions anti-imperialist. It stands out how the anti-hegemonic dimension has been present every time there were real advances in this process of integration. It analyzes the role and the possibilities that the popular struggles have in it and which are the spaces of construction of these articulations and identity searches. Also how this process of integration from below, from the peoples, from the popular organizations can contribute to rethink the so-called Theory of International Relations from Latin America in a epistemic-political decolonizing approach. The concept of Latin American Ñandereko is proposed, starting from the Guarani idea of a contrastive, intercommunitarian identity that affirms an egalitarian community life among men and in deep relation with nature, as a source of inspiration in the construction of Latin American resistance and union identities.

\section{KEYWORDS}

Latin America; Counterhegemonic Integration; Identity; resistance; Latin American Ñandereko. https://doi. org/10.15366/relacionesinternacionales2018.39.007 


\section{ntroducción}

La larga lucha de los pueblos latinoamericanos por estar unidos y por poder llevar adelante un proyecto autónomo de vida política, económica y cultural ha llevado, frente al continuo acecho imperialista, a que se configuren -con límites, parcialidades y ambigüedadeselementos de una búsqueda de integración contrahegemónica y de identidades de resistencia. Esta configuración política necesita estar acompañada de un planteo epistémico propio, original y creativo, especialmente en el campo de las Ilamadas relaciones internacionales. En este trabajo realizo un planteo de esa doble búsqueda.

En el primer punto del trabajo abordo la importancia del camino contrahegemónico en la integración latinoamericana. Comienzo explicando en qué sentido se asume el concepto de integración y, luego, por qué es importante comprender que, tanto en la historia de nuestra región como en su actualidad, la dimensión contrahegemónica ha sido la que posibilitó dar pasos concretos en este proceso. Explico cómo esta dimensión tiene un doble aspecto político y epistémico indisolublemente unidos $y$, por tanto, exige un cambio descolonizador en la construcción latinoamericana de lo que suelen llamarse "relaciones internacionales". Destaco, finalmente, la importancia que tiene esto en la coyuntura regional y mundial, dada una situación actual que implica un "empate hegemónico" entre las fuerzas con una impronta popular que predominaron al comenzar el siglo y el avance de las fuerzas de derecha en los últimos años. Para la comprensión de este proceso propongo la recuperación de la comprensión del carácter imperialista que configura una globalización dominada fundamentalmente por los Estados Unidos.

En el segundo punto presento la importancia del aporte indígena para pensar una identidad de resistencia y un planteo contrahegemónico de la integración latinoamericana. Recurro para esto al pensamiento de José Carlos Mariátegui, primero, y luego, al aporte más reciente de los movimientos indígenas en nuestra región. Planteo aquí algunas líneas, inspiradas en los planteos indígenas, que pueden ayudarnos a repensar contrahegemónicamente las llamadas relaciones internacionales en y desde América Latina.

En el tercer punto planteo el valor de la articulación de las luchas populares para una integración pensada principalmente desde los pueblos, "desde abajo". Destaco, especialmente, las articulaciones que se fueron realizando en relación a la Alternativa Bolivariana para las Américas (ALBA) en la búsqueda de un modo propio de integración con esta direccionalidad popular. Rescato aquí las propuestas de Amado Luiz Cervo para repensar las relaciones internacionales desde nuestra historia. Finalmente enumero algunos espacios de concretización de estas articulaciones contrahegemónicas.

En el cuarto punto propongo el concepto de ñandereko latinoamericano, tomando del principio de la cosmovisión guaraní elementos para repensar una identidad afirmada de resistencia al imperialismo capitalista y/o colonial marcada por una praxis basada en lo comunitario tanto en relación con los demás seres humanos como en relación a la naturaleza, entendida desde las cosmovisiones indígenas.

Concluyo proponiendo las fuentes de esta búsqueda en la necesidad de la construcción de un pensamiento contrahegemónico de las llamadas relaciones internacionales que 
acompañe el camino alternativo y autónomo de integración.

\section{El camino contrahegemónico de la integración latinoamericana}

Entiendo importante aclarar que utilizo aquí el término "integración" porque ha sido consagrado fuertemente como sinónimo de un camino conjunto de los países de la región. Todo término tiene su carga histórica y sus limitaciones. Por eso queremos, en este trabajo, desvincular el término del concepto de desarrollo, del cual fue pareja casi inseparable en los planteos de las teorías desarrollistas y ahorrarle cualquier vínculo con una interpretación economicista o, también, de asimilacionismo cultural. En cuanto a su economicismo, principalmente desligarlo de cualquier vínculo con un planteo necesariamente capitalista al que, sobre todo desde su cercanía al concepto de desarrollo, podría quedar asociado en su interpretación.

En esta misma línea agrego el adjetivo de contrahegemónico para dejar claro el único camino que históricamente ha permitido un recorrido conjunto fecundo de nuestros países: el de proponerse un proceso de liberación de los lazos imperialistas impuestos por Estados Unidos en la región y recuperar así su capacidad autónoma de pensarse y proyectarse a sí mismos en unión. Con sus límites y ambiguedades, el proceso vivido en la región en los últimos quince años muestra la importancia de esta constatación. Importancia que se acrecienta por la particularidad de que, como región, América Latina constituyó prácticamente la única que mostró un grado considerable, tanto por su contenido como por su extensión, de contestación al neoliberalismo ${ }^{1}$.

Un camino político de este tipo tiene necesariamente que estar acompañado de un camino epistémico. La praxis contrahegemónica en lo político necesita de una descolonización del conocimiento elaborada desde una reconstrucción y revalorización de las memorias de las luchas populares por la liberación regional y por una reflexión de esa misma praxis política contrahegemónica. Esto es particularmente necesario porque el ámbito académico de las relaciones internacionales es uno de los más colonizados por el predominio casi absoluto de la producción de conocimiento desde los centros de poder y, con una clara preponderancia, de los ligados a los poderes norteamericanos. Puede afirmarse que en ella es donde más se da aquello de que se transforman "los intereses hegemónicos en conocimientos verdaderos" ${ }^{2}$. En este planteo de la necesidad e indisolubilidad de lo político y lo epistémico, el aporte de los movimientos indígenas ha sido fundamental en la bisagra de los dos milenios en nuestra América Latina.

En la medida en que nuestra región se fue independizando jurídicamente de sus metrópolis coloniales, fundamentalmente en el siglo XIX, el proceso de inserción dependiente en la división internacional del trabajo que generó el capitalismo fue limitando su capacidad autonómica y fue asumiendo objetivos extraños elaborados desde los centros de poder mundial. Así, las ideas unionistas para la región de muchos de los líderes y pensadores

1 GAMBINA, Julio C., Los cambios en el sistema mundial y el lugar de América Latina en la lucha por el socialismo en Seminario "Rosa Luxemburg, pensamiento y acción por el socialismo. América Latina en el siglo XXI", FISyP, Buenos Aires, octubre 2005, p. 51: http://www.rosa-luxemburg-club.de/fileadmin/rls_uploads/pdfs/Themen/ Ausland/Seminario_RL.pdf [Consultado el 16 de marzo de 2018]

2 CAIRO CAIROU, Heriberto y BRINGEL, Breno, "Articulaciones del Sur Global: afinidad cultural, internacionalismo solidario e Iberoamérica en la globalización contrahegemónica" en Geopolítica(s), vol. 1, n 1, 2010, p. 45. 
de aquella independencia fueron dejando paso a una conformación de estados oligárquicos cuya referencia primera, y en muchos casos casi absoluta, fueron las metrópolis centrales, principalmente Inglaterra, primero, y, posteriormente, Estados Unidos. Esta profunda limitación en la relación y en la posibilidad de gestar procesos de articulación regional está expresada en lo que sostenía Juan Carlos Puig: "Tal vez porque los objetivos no fueron propiamente autonómicos es que no han avanzado decididamente los procesos de integración en América Latina"'3.

Por eso conviene recordar que los pasos importantes en procesos de integración latinoamericana estuvieron siempre de la mano de posiciones antiimperialistas y contrahegemónicas. Esto estuvo presente en la historia de las reuniones y congresos que se hicieron tanto en el siglo XIX como en el XX, que fueron siempre respuestas a "amenazas externas" ${ }^{\prime \prime}$. Este hecho se reprodujo en las últimas décadas en nuestra región:

"... es necesario no perder de vista que la mayoría de los recientemente creados espacios y esquemas de integración inaugurados en América Latina se caracterizan por su carácter reactivo y/o defensivo en su exclusión de EEUU, en función del histórico fantasma de la amenaza de una influencia o una injerencia del hegemón hemisférico. De hecho, para bien o para mal EEUU sigue constituyendo un referente fundamental en estos procesos y sigue incidiendo sobre su configuración, así fuere en otro rol, dando continuidad y renovado vigor al principio de soberanía nacional"5.

Es importante la reflexión sobre esta experiencia de la construcción de una integración regional contrahegemónica y, sobre todo, la de estos últimos años en América Latina. Aunque se pueda poner en duda la actualidad de esta afirmación desde la interpretación que ve la coyuntura contemporánea como un fin de ciclo populista, progresista o de izquierda, como se prefiera Ilamarlo. Frente a esto, prefiero hablar aquí de un tiempo de "empate catastrófico" que implica una no definición clara del proceso adveniente en la región ${ }^{6}$. Entiendo que, aún tomando cualquiera de las dos lecturas de la realidad latinoamericana, ese análisis vale, claramente, la pena. Pero en el caso de que pueda interpretarse, como propongo, en la línea de un "empate catastrófico", es más necesario todavía, porque puede alimentar la construcción de un nuevo impulso integrador con la riqueza de la reflexión sobre aciertos, equivocaciones y priorizaciones claves en este proceso. Seguir pensando y actuando en este sentido requiere

3 PUIG, Juan Carlos, apud RUSSEL, Roberto y TOKATLIAN, Juan Gabriel, "De la autonomía antagónica a la autonomía relacional: una mirada teórica desde el Cono Sur" en Perfiles latinoamericanos, no 21, diciembre, 2002, p. 170.

4 BRICEÑO RUIZ, José, "Autonomía: genealogía y desarrollo de un concepto. Su relación con el regionalismo en América Latina" en Cuadernos sobre Relaciones Internacionales, Regionalismo y Desarrollo, Vol. 9, no 18, juliodiciembre, 2014, p. 14.

5 SERBIN, Andrés, "Regionalismo y soberanía nacional en América Latina: los nuevos desafíos" en Documentos CRIES, no 15, Nueva Sociedad / CRIES, Buenos Aires, 2010, p. 17.

6 Sin entrar a un desarrollo pleno de esta postura, entiendo que el escenario latinoamericano actual puede ser explicado más adecuadamente si damos importancia a una realidad que se repite en muchos países y que se expresa en resultados electorales donde aparece una división en dos mitades equitativas. Relaciono esto con dos interpretaciones latinoamericanas del concepto de empate - de raíz gramsciana-: la de Juan Carlos Portantiero, en los años setenta, como "empate hegemónico" y la más reciente de Álvaro García Linera como "empate catastrófico". Cf. PORTANTIERO, Juan Carlos, Clases dominantes y crisis política en la Argentina actual, BVU, Buenos Aires, 2013; y GARCÍA LINERA, Álvaro, "Empate catastrófico y punto de bifurcación" en Crítica y emancipación. Revista latinoamericana de Ciencias Sociales, Vol. 1, no 1, Buenos Aires, CLACSO, pp. 23-33. 
un análisis evaluativo de esta experiencia inédita.

Por otro lado, conviene reafirmar la actualidad de una interpretación que reafirme el carácter imperialista que rige el proceso que suele denominarse "globalización". Esta recuperación temática es fundamental. Ya Atilio Borón planteaba este tema con contundencia hace unos años7. Puig, mucho antes, sostenía que "(...) Estados Unidos representa la fuerza extrarregional que obstaculiza la integración"8. Este tipo de caracterización de la dominación norteamericana en este contexto es importante ante cierta reticencia al uso de este concepto:

"(...) lo que define el curso de la dominación capitalista en la actualidad es la hegemonía de Estados Unidos, ejercida con un específico carácter imperialista y que se expresa en forma particular respecto a América Latina, históricamente pretendida como su 'patio trasero'"'9.

Algunos autores afirman que cuanto más ofensiva se torna la presencia norteamericana más reacción provoca:

"Acertada o incorrectamente, cuanto más Estados Unidos hizo su presencia como monstruo industrial, supremo jefe militar, y conocido omnívoro cultural, más latinoamericanos llegaron a ver -o imaginar - los vínculos entre estos papeles, y rechazaron esta dinámica"10.

También es importante tener en cuenta la postura que señala la importancia de que el desarrollo de un planteo contrahegemónico tiene una base en el contexto del estado-nación. Así se plantea desde la vertiente gramsciana de lectura de las relaciones internacionales:

"De hecho, el enfoque de Cox ha sido el de los bloques históricos que sustentan a determinados estados y de cómo éstos se conectan a través de los intereses mutuos de las clases sociales en diferentes países. Además, siguiendo tanto a Gramsci como a Cox, el contexto nacional es el único lugar donde se puede fundar un bloque histórico y donde debe comenzar la tarea de construir un nuevo bloque histórico, como base para la contrahegemonía para cambiar el orden mundial"11.

7 BORÓN, Atilio, "Hegemonía e imperialismo en el sistema internacional" en CHOMSKY, Noam et al. (ed.), Nueva Hegemonía Mundial. Alternativas de cambio y movimientos sociales, Buenos Aires, CLACSO, 2004, pp. 71-83.

8 PUIG, Juan Carlos, "Derecho internacional americano, nacionalismo latinoamericano y régimen internacional" en Mundo Nuevo. Revista de Estudios Latinoamericanos. n 1, Instituto de Altos Estudios de América Latina / Universidad Simón Bolívar, Caracas, julio-septiembre, 1978, p. 96.

9 RAJLAND, Beatriz, La estrategia imperialista hoy. Aspectos políticos de la integración en la actualidad y el papel de los Estados Unidos en su relación con América Latina en Seminario "Rosa Luxemburg..., op.cit., 2005, pp. 30-31.

10 McPHERSON, Alan, "Myths of Anti-Americanism. The Case of Latin America" en The Brown Journal of World Affairs, Vol. 10, no 2, invierno-primavera, 2004, p. 141. La traducción es mía y el texto original en inglés dice así: "Rightly or wrongly, the more the United States made its presence as an industrial juggernaur, military overlord, and cultural omnivore known, the more Latin Americans came to see -or imagine-links between these roles, and the move they rejected them".

${ }^{11}$ BIELER, Andreas y MORTON, Adam David, "A critical theory route to hegemony, world order and historical change: neo-Gramscian perspectives in International Relations", en Capital \& Class, Vol. 28, no 1, marzo, 2004, pp. 101-102. La traducción es mía. El texto original en inglés dice así: "Indeed, Cox's focus has been on historial blocs underpinning particular states and how these are connected through the mutual interests of social classes in different countries. Further, following both Gramsci and Cox, the national context is the only place where an historial bloc can be founded and where the task of building new historial bloce, as the basis for counterhegemony to change world orden, must begin". 
Sin embargo, al analizar los movimientos sociales transnacionales, hay autores que colocan el acento en este tipo de actores en la lucha contrahegemónica ${ }^{12}$. Aunque, para algunos autores, Gramsci no tiene una teoría de la contrahegemonía ${ }^{13}$, para otros hay claramente en él una "perspectiva" o "concepción" contrahegemónica que es altamente valorada para explicar las características de los movimientos de contestación al neoliberalismo que tienen lugar y desarrollo en la actualidad ${ }^{14}$.

\section{El aporte indígena}

Tanto en la producción académica como en la reflexión política más amplia, hay un importantísimo aporte de autores latinoamericanos para poder pensar la integración latinoamericana desde un planteo contrahegemónico. Quiero quedarme aquí con algunos elementos que fueron apareciendo gracias a la acción de los movimientos indígenas. La valiosísima originalidad de algunos autores estuvo muy relacionada con su compromiso con estos movimientos.

Uno de ellos es José Carlos Mariátegui. Si bien hay un importante movimiento de recuperación del pensamiento y la praxis de este enorme intelectual y político peruano, no siempre se ha insistido en sus planteos para repensar las relaciones internacionales y la integración latinoamericana. El amauta sostiene que es la penetración imperialista la que acentúa el carácter "semicolonial" de la situación latinoamericana. Este carácter se refuerza al impulsar la división entre los países latinoamericanos: "... lo que separa y aísla a los países latinoamericanos..." es que "funcionan como colonias de la industria y la finanza europea y norteamericana"15.

A pesar de esta situación lamentable, la colonialidad terminó dando elementos comunes a América Latina que pueden ser componentes de una base de unidad:

Los pueblos de la América española se mueven en una misma dirección. La solidaridad de sus destinos históricos no es una ilusión de la literatura americanista. Estos pueblos, realmente, no sólo son hermanos en la retórica, sino también en la historia. Proceden de una matriz única. La conquista española, destruyendo las culturas y las agrupaciones autóctonas, uniformó la fisonomía étnica, política y moral de la América Hispana ${ }^{16}$.

Sostiene que existe una relación profunda entre antiimperialismo y anticapitalismo ${ }^{17}$. Por esto vincula el "carácter internacional de la revolución socialista" con "la posibilidad

12 DE LA TORRE, Verónica, "La acción colectiva transnacional en las teorías de los movimientos sociales y de las Relaciones Internacionales" en CONfines, Vol. 7, no 14, agosto-diciembre, 2011, p. 47.

${ }^{13}$ BURAWOY, Michael, "Sociological Marxism: The Complementary Convergence of Antonio Gramsci and Karl Polanyi" en Politics \& Society, Vol. 31, n 2, 2003, p. 213.

${ }^{14}$ CARROLL, William K. y RATNER, R. S., "Between Leninism and Radical Pluralism: Gramscian Reflections on Counter-Hegemony and the New Social Movements" en Critical Sociology, Vol. 20, no 3, 1994, p. 7.

15 MARIÁTEGUI, José Carlos, Invitación a la vida heroica, Fondo Editorial del Congreso del Perú, Lima, 2005, p. 451.

${ }^{16}$ Ibídem, p. 451.

17 GERMANÁ, César, El "Socialismo Indo-Americano" de José Carlos Mariátegui: Proyecto de reconstitución del sentido histórico de la sociedad peruana, Amauta, Lima, 1995, pp. 87.118. 
de concebir de manera realista la unidad de los pueblos de América Latina"18. La unidad latinoamericana tenía que ver con una opción socialista, superadora de un capitalismo al que era totalmente inútil tratar de integrarse:

"A Norteamérica capitalista, plutocrática, imperialista, sólo es posible oponer eficazmente una América latina o íbera, socialista. La época de la libre concurrencia en la economía capitalista ha terminado en todos los campos y todos los aspectos. Estamos en la época de los monopolios, vale decir de los imperios. Los países latinoamericanos llegan con retardo a la competencia capitalista. Los primeros puestos están ya definitivamente asignados. El destino de estos países, dentro del orden capitalista, es de simples colonias."19

El proyecto político y económico latinoamericano tenía que ser original, propio. No tenía que seguir, ni en lo político, ni en lo epistémico, ninguna receta extraña, ni siquiera de la izquierda que combatía el capitalismo. De allí su emblemático párrafo en Aniversario y Balance que propone este camino:

"No queremos, ciertamente, que el socialismo sea en América calco y copia. Debe ser creación heroica. Tenemos que dar vida, con nuestra propia realidad, en nuestro propio lenguaje, al socialismo indoamericano. He aquí una misión digna de una generación nueva"20.

Esta originalidad y potencialidad autónoma estaba dada también por la búsqueda del sujeto revolucionario al que habilita pensar también como sujeto de la unión latinoamericana, no exclusivo, pero nuclear: los movimientos indígenas. Así él impulsa una "búsqueda del proletariado" tanto en su dimensión política como epistémica y encuentra en los pueblos indígenas "la fuente principal de la energía revolucionaria"21.

Esta postura clara en la búsqueda de los sujetos político-epistémicos necesarios para América Latina está relacionada con su crítica a una esperanza en el protagonismo de las burguesías. Esperanza que tenía buena parte de la izquierda y que causó un daño muy grande en su potencialidad revolucionaria. Él sostuvo que "en América Latina no había fundamento histórico para ninguna 'burguesía nacional'..."22. Esto imposibilitaba pensar en esta supuesta burguesía nacional como sujeto de la integración regional, y no es posible - para él- la unidad latinoamericana bajo este protagonismo y este sistema:

"Hispanoamérica, Latinoamérica, como se prefiera, no encontrará su unidad en el orden burgués. Este orden nos divide, forzosamente en pequeños nacionalismos. Los únicos que trabajamos por la comunidad de estos pueblos somos, en verdad, los socialistas, los revolucionarios" 23 .

Así, el horizonte de integración latinoamericana coincide con el de la superación del

\footnotetext{
${ }^{18}$ Ibídem, p. 143.

19 MARIÁTEGUI, José Carlos, Invitación a la vida..., op.cit., p. 451.

${ }^{20}$ Ibídem, p. 452.

${ }^{21}$ FLORES GALINDO, Alberto, Obras completas. T. V. Sur, Lima, 2008, pp. 371.362.

22 QUIJANO, Aníbal, "Estado-nación y 'movimientos indígenas' en la región Andina: cuestiones abiertas" en OSAL, Vol. 6, no 19, CLACSO, Buenos Aires, julio, 2006, p. 22.

${ }^{23}$ MARIÁTEGUI, José Carlos, Invitación a la vida..., op.cit., p. 464.
} 
capitalismo: "A la Norteamérica sajona le toca coronar y cerrar la civilización capitalista. El porvenir de la América Latina es socialista"24.

El trabajo de Mariátegui, inacabado pero inmensamente sugerente como camino político y epistémico, nos pone de frente al aporte de este sujeto tan profundamente latinoamericano como lleno de potencialidad revolucionaria que son los movimientos indígenas en nuestra región.

Entiendo que desde allí y desde todas las mayorías populares latinoamericanas, desde sus sabidurías forjadas en las praxis de lucha, puede repensarse tanto la integración latinoamericana como el proyecto político y epistémico original que nos debemos en nuestra región. Este es el "lugar" epistémico-político desde el cual repensar. Como decía hace unos cuantos años el admirable y poco difundido Rodolfo Kusch, que había que "(...) replantear el problema del pensamiento desde el subsuelo mismo de nuestra sociedad"25, entendiendo este "subsuelo" en su doble sentido: como lo más profundo en autenticidad arraigada y desde quienes ocupan socioeconómicamente el último lugar -el más "bajo"- en nuestras sociedades capitalistas.

Como señala muy acertadamente el costarricense Willy Soto Acosta, las Ciencias Sociales en América Latina - y él lo plantea pensando en las relaciones internacionales y en la integración latinoamericana - "presentan dos grandes retos: desprenderse del eurocentrismo y del átomo epistemológico, teórico y metodológico del estado-nación"26. Y si hay un sujeto epistémico que puede responder a estos dos grandes retos profunda y radicalmente, descolonizar (superando el eurocentrismo) y trascender el estadocentrismo, ese sujeto son los movimientos indígenas. Una expresión de esta capacidad es el enorme aporte que realizaron para el Nuevo Constitucionalismo Latinoamericano - expresado fundamentalmente en los procesos y los textos constitucionales ecuatoriano y boliviano-, justamente en estos dos sentidos.

Y paso a intentar brindar algunos elementos para justificar estas afirmaciones. Primero: todo el planteo descolonizador, solamente ha sido fecundo en la medida en que los intelectuales que lo proponen o son indígenas, o están ligados y comprometidos profundamente con los movimientos indígenas. Por eso, si queremos pensar en una descolonización de las relaciones internacionales y de la integración, lo indígena tiene que ser una de las fuentes claves, nucleares.

Segundo: porque el planteo más profundo de repensar el estado en nuestra región lo han realizado los movimientos indígenas y esto quedó expresado fundamentalmente

${ }^{24}$ Ibídem, p. 464.

${ }^{25} \mathrm{KUSCH}$, Rodolfo, Esbozo de una Antropología Filosófica Americana, Castañeda, Buenos Aires, 1978, p. 73. En este tema del "lugar" epistémico-político desde el cual replantear la construcción del conocimiento -y también de la praxis política - en América Latina también me parece clave el aporte que hace desde la teología y la filosofía de la liberación, uno de los mártires de la lucha contrahegemónica latinoamericana como es Ignacio Ellacuría. Cf. ELLACURÍA, Ignacio, Los pobres, lugar teológico en América Latina. Archivo Chile, CEME, Santiago de Chile.

${ }^{26}$ SOTO ACOSTA, Willy, "Introducción" en SOTO ACOSTA, W. (ed.), Ciencias Sociales y Relaciones Internacionales: nuevas perspectivas desde América Latina, Escuela de Relaciones Internacionales de la Universidad Nacional / CLACSO, Heredia, 2015, p. 26. 
en dos grandes conceptos que están intrínsecamente relacionados: plurinacionalidad e interculturalidad. Estos dos conceptos desarman el andamiaje procapitalista que configuró a los estados-nación en nuestra región.

Hay algunas consecuencias inmediatas de estos planteos para repensar las llamadas relaciones internacionales. Si entendemos que nuestros países son plurinacionales, las relaciones internacionales son otra cosa que lo que se estudia en nuestros colonizados cursos universitarios. Entiendo que podría afirmarse que no hay "disciplina" más colonizada y más estadocéntrica que lo que denominamos "relaciones internacionales" y, atendiendo a lo que apuntaba Soto Acosta más arriba, el planteo indígena es una enorme fuente crítica a estas dos realidades, y a la vez una enorme fuente de construcción de pensamiento alternativo frente a estos "dos grandes retos".

Entiendo que desde una perspectiva latinoamericana hay que pensar en una superación radical de los contenidos y direccionamientos hegemónicas en este tipo de construcción de conocimiento que se denominan "Teorías de las Relaciones Internacionales". Habría más bien que pensar en "Teorías de las Relaciones Transestatales" si somos coherentes con una afirmación de la plurinacionalidad de nuestros estados en la región. Esto no implica negar la importancia de las relaciones entre los estados, pero sí implica trascenderlas, y hacerlo, no desde las multinacionales o las corporaciones financieras, sino desde abajo, desde los pueblos, desde los movimientos populares y, por su potencialidad epistémica, principalmente desde los pueblos indígenas. Había ya "relaciones internacionales" entre los pueblos indígenas antes de la invasión europea. Eso jamás se estudia en la disciplina oficial27.

Los pueblos y naciones indígenas nos marcan dos formas de transestatalidad que conviene tener en cuenta al repensar este ámbito de conocimiento. Son transestatales diacrónicamente, porque trascienden a los estados por preexistentes. Había -y aún existennaciones antes de que se formaran los estados latinoamericanos. No fueron tenidas en cuenta cuando se formaron los estados-nación o, mejor dicho, fueron masacradas e invisibilizadas para poder configurar nuestros estados-nación. Sin embargo, en un admirable ejercicio de uso contrahegemónico de los conceptos hegemónicos, los pueblos indígenas retomaron y resignificaron el concepto de "nación" —en nombre de la cual habían sido siempre perseguidosy lo enarbolaron como algo propio, resignificándolo contrahegemónicamente. Pero también los pueblos y las naciones indígenas son transestatales sincrónicamente, y muchas de las fronteras latinoamericanas son "testigos" de esa realidad. Hay muchas naciones indígenas que existen en distintos estados. Uno de estos casos es el del pueblo guaraní, que se distribuye -al menos- en Argentina, Brasil, Paraguay y Bolivia. Trascienden a los estados porque la misma Nación está cruzando todas esas fronteras inventadas colonialmente. Um dirigente

\footnotetext{
${ }^{27}$ Hay trabajos - preferencialmente de historia, antropología y arqueología- que expresan esta realidad. Pueden verse, por ejemplo, la primera parte de BETHELL, Leslie (ed.), Historia de América Latina. 1. América Latina colonial: la América Precolombina y la Conquista, Crítica, Barcelona, 1990; BOUCHARD, Jean-François y GUINEA, Mercedes (eds.), Relaciones interculturales en el área ecuatorial del Pacífico durante la época precolombina, BAR International, Oxford, 1989; IBARRA ROJAS, Eugenia y SALGADO GONZÁLEZ, Silvia, "Áreas culturales o regiones históricas en la explicación de relaciones sociales de pueblos indígenas de Nicaragua y Costa Rica de los siglos XV y XVI" en Anuario de Estudios Centroamericanos, no 35-36, Universidad de Costa Rica, 2010. En el área de lo que se reconoce como disciplina de Relaciones Internacionales hay una breve referencia en DÍAZ MARTÍNEZ, Karla, "Diplomacia de los Pueblos, propuesta contrahegemónica en las Relaciones Internacionales" en Revista Búsquedas Políticas, Vol. 2, nº 1, Universidad Alberto Hurtado, 2013, p. 217.
} 
puruhá del Chimborazo en Ecuador, Julián Pucha, me decía hace unos años:

"En América Latina, al menos, tenemos nuestros hermanos. Por ejemplo, en la frontera peruano-ecuatoriana, que son nuestra familia y que por haber puesto ese río de frontera ahí tienen que estar matándose entre hermanos. No creemos que sea justo. Estamos hablando de una integración latinoamericana, eso ya se está viviendo, no es nuevo, (...) por eso los pueblos indígenas han formado una Coordinadora Andina de los Pueblos Indígenas, que ojalá que eso vaya creciendo, pero eso es una lucha con proyección a muchos años"28.

Esta es una de las razones para que pensemos desde otras perspectivas, desde otro lugar epistémico-político las relaciones internacionales y nos animemos a matar su configuración básica dada fundamentalmente por el Departamento de Estado y por el Pentágono - y si nos cabe alguna duda de eso estudiemos la biografía y la hoja de servicios de sus referentes principales-, y a hacer el ejercicio de "creación heroica" que pedía Mariátegui pensando la realidad que trasciende a los estados desde nuestros pueblos, sus necesidades, sus praxis de lucha, sus búsquedas. Seguiremos estudiando a los estados, a las multinacionales, a las corporaciones financieras, pero desde ahí, desde ese otro lugar epistémico y político.

Pero también esa trascendencia implica pensar más allá del estado capitalista. Implica pensar desde otras formas de organizar la economía, la política, la resolución de conflictos. Y aquí, lo que se ha expresado como la propuesta del "buen vivir" es clave y tiene que entrar en diálogo con otras propuestas contrahegemónicas que estuvieron y están en el corazón de las luchas populares de la región en la búsqueda de una superación del capitalismo, en la creación heroica de un "Socialismo Indoamericano" como pedía Mariátegui. La integración latinoamericana necesita una propuesta original, que no sea calco ni copia. El planteo indígena del "buen vivir" es un aporte fundamental para la construcción de esa propuesta y aquí hay otro elemento para pensar las relaciones transestatales.

\section{Unión de las luchas populares y su aporte a la integración}

$\mathrm{Si}$, en la línea de una filosofía de la praxis latinoamericanamente entendida $-\mathrm{y}$ aquí retomamos una vez a Mariátegui- entendemos a la lucha de las mayorías populares ${ }^{29}$ como fuente principal de construcción epistémica, entonces la articulación de esas luchas es uno de los grandes retos políticos y epistémicos y una de las grandes fuentes para repensar la integración latinoamericana.

Pensar la integración desde los pueblos, nucleada en la articulación de los movimientos populares significa, por un lado, un intento de superación del estadocentrismo desde abajo. Esto implica también considerar como sujetos centrales del proceso de unión latinoamericana a los pueblos. Hay algunos autores que, en relativa cercanía con esto, proponen "incluir a las masas en el estudio de las relaciones internacionales" ${ }^{\prime \prime 2}$. La importancia de esta

\footnotetext{
28 PUCHA, Julián, Dirigente indígena del Chimborazo, Riobamba, entrevista realizada por el autor, enero, 2009.

${ }^{29} \mathrm{Al}$ hablar de la praxis de las luchas populares me refiero tanto a las más organizadas y amplias políticamente, como a las cotidianas en el interior de cada familia, como la de poder dar de comer a los hijos cada día en medio de la más injusta pobreza.

30 TICKNER, Arlene B.; CEPEDA M., Carolina y BERNAL, José Luis, "Anti-Americanismo, Pro-Americanismo y sentido
} 
articulación contrahegemónica es captada por autores norteamericanos que entienden que: "(...) un problema mayor es el grado en que las formas de insurgencia se fusionarán como contrahegemonía antiamericana dentro y a través de las regiones del mundo"31.

Pero la importancia para nuestros pueblos está relacionada a que la integración latinoamericana solamente tiene sentido si plenifica, enaltece, enriquece y hace más justa la vida de los pueblos latinoamericanos y caribeños. Para esto hay que preguntarse -en la línea de Mariátegui- por quiénes son los sujetos de la integración ${ }^{32}$.

El proceso reciente de avance de la integración latinoamericana tuvo varios límites y ambigüedades, pero quizás la mayor haya sido suponer a las "burguesías nacionales" - si es que existen y que alguna vez existieron en nuestra región-como sujetos protagónicos de la integración. El proceso "integrador" de la Iniciativa para la Integración de la Infraestructura Regional Sudamericana (IIRSA) ${ }^{33}$ es quizá la muestra más clara de esa ambigüedad. Por esto es necesario tener claro quiénes son los sujetos de la integración, tanto en lo político como en lo epistémico.

Entre las iniciativas institucionales fue sin duda el ALBA el que planteó claramente su dimensión contrahegemónica ${ }^{34} \mathrm{y}$, consecuentemente, el papel fundamental de la articulación de los movimientos sociales:

"(...) ALBA se ubica en oposición a las políticas imperialistas en la región.

(...) Avanzar en la organización social y construir alianzas estratégicas será decisivo para obtener victorias. Así, la participación de los movimientos sociales y organizaciones políticas tiene un rol protagónico en esta construcción" ${ }^{\prime \prime 3}$.

Esta incorporación de los movimientos sociales trae consigo elementos distintos para la teoría de la integración:

"De esta forma se elabora un bloque regional inspirado en parámetros distintos a los de la teoría clásica de la integración y en contraposición a ciertos fundamentos de la teoría tradicional de las relaciones internacionales"36.

No se trata aquí solamente de una versión resucitada del "internacionalismo proletario", aunque de ninguna manera se opone a él, sino que esta visión se enriquece, se historiza, y

común en América Latina" en Foro Internacional, Vol. 55, n 3, 2015, p. 806

${ }^{31}$ KNAUFT, Bruce M., "Provincializing America. Imperialism, Capitalism, and Counterhegemony in the Twenty-first Century" en Current Anthropology, Vol. 48, n 6, diciembre, 2007, p. 791. La traducción es mía. El texto original en inglés dice así: "A larger issue is the degree to which forms of insurgency will coalesce as anti-American counterhegemony within and across world regions".

32 RAJLAND, Beatriz, "La estrategia imperialista...", op.cit., p. 38.

${ }^{33}$ La IIRSA constituye una iniciativa para interconectar las distintas regiones de Sudamérica mediante la construcción de grandes carreteras, hidrovías y puertos. El aplastante protagonismo del empresariado y del poder financiero en estas iniciativas provocó y provoca innumerables conflictos comunitarios y ambientales.

${ }^{34}$ GAMBINA, Julio C.; RAJLAND, Beatriz y Daniel CAMPIONE, ¿Hacia dónde va la integración regional de Nuestra América? Un balance necesari, FISyP, Montevideo, 2014, p. 30.

35 STÉDILE, João Pedro; PIÑERO, Joaquín y BERTOLDI, Manuel, "La integración desde los pueblos" en LEÓN, Irene (coord.), La ALBA: el horizonte latinoamericano del Siglo XXI, FEDAEPS / ALAI, Quito, 2014, p. 135.

${ }^{36}$ GAMBINA, Julio C. et al., ¿Hacia dónde va..., op.cit., p. 33. 
se sitúa en nuestra realidad latinoamericana. Ambas son claramente luchas anticapitalistas y esto es uno de los elementos que las hacen converger:

"Más bien, el 'principio unificador del socialismo' puede no ser de clase, sino la resistencia al capital. Los movimientos sociales pueden o no alinearse con algún aspecto de la identidad de la clase obrera, pero en cualquier caso la dinámica totalizadora del capitalismo probablemente sea un factor extradiscursivo común en sus luchas multiformes. En la medida en que estas luchas incorporen una resistencia al poder del capital de alguna manera, existe una base sólida en su práctica para la formación de coaliciones contrahegemónicas. Este terreno común no tiene por qué ser la base única para conseguir alianzas progresistas, pero es probable que resulte especialmente duradero en el sostenimiento de tales coaliciones en coyunturas sucesivas" ${ }^{\prime 3}$.

En la articulación se fue gestando "la identidad de pertenencia" que ha sido clave para establecer diálogos entre las distintas organizaciones populares de la región ${ }^{38}$. Esta identidad también tiene un componente importante en su oposición al poder norteamericano. La Carta de los Movimientos Sociales de las Américas hacia el ALBA habla de:

"La recreación de un nuevo internacionalismo de pueblos en lucha, a través de una auténtica perspectiva de integración popular que sea plural, horizontal, con una clara definición ideológica antineoliberal, anticapitalista, antipatriarcal y antiimperialista" ${ }^{\prime \prime}$.

La Carta de los Movimientos Sociales de las Américas hacia el ALBA dentro del Foro Social Mundial en Belem de Pará en 2009 constituye un precioso documento para repensar en esta línea la llamada teoría de las Relaciones Internacionales y la teoría de la integración desde una perspectiva popular. Así puede plantearse una integración desde abajo:

"(...) nuestro horizonte fundamental es la integración desde abajo, a partir de los pueblos, para impulsar transformaciones antineoliberales y antiimperialistas, que rescaten las formas alternativas y solidarias de intercambio que hemos creado en nuestros territorios para enfrentar la dominación neoliberal. La memoria y las luchas que hemos compartido se convierten en un acumulado de fuerzas que sostienen este sueño de unidad por la construcción de un continente justo, libre de hegemonías imperialistas, de poderes patriarcales y donde germine el buen vivir entre los pueblos" ${ }^{\prime 40}$.

\footnotetext{
${ }^{37}$ CARROL, William K. y RATNER, R.S., "Between...", op.cit., p. 18. La traducción es mía. El texto original en inglés dice así: "Rather, the 'unifying principle of socialism' may not be class, but resistance to capital. Social movements may or may not align themselves with some aspect of working-class identity, but in any case capitalism's totalizing dynamic is likely to be a common extra-discursive factor in their multiform struggles. To the extent that these struggles incorporate a resistance to the power of capital in some way, there is a strong basis in their practice for counter-hegemonic coalition formation. Such common ground need not be the sole basis for pursuing progressive alliances, but it is likely to prove especially durable in sustaining such coalitions across successive conjunctures".

38 STÉDILE, João Pedro et al., "La integración...", op.cit., p. 136.

39 ASAMBLEA DE LOS MOVIMIENTOS SOCIALES, "Construyendo la integración desde abajo de los pueblos. Impulsando el ALBA y la solidaridad de los pueblos, frente al proyecto del imperialismo" en Rebelión, 2 de febrero de 2009, www.rebelion.org/noticias/2009/2/80099.pdf [Consultado el 14 de febrero de 2018]

${ }^{40}$ Ibídem.
} 
En las teorías de las Relaciones Internacionales existe un planteo, realizado en 2008 por David Blaney e Inayatullah Naeem, de una integración desde abajo: "International Relations from Below"41. La revisión de la teoría es necesaria porque ésta fue tradicionalmente y fundamentalmente elaborada desde los centros de poder norteamericanos, como las teorías de la integración, que tienen fuertemente marcado un modelo europeo. Este predominio atribuible principalmente a la dominación política y militar que influyen decisivamente en el área- sigue claramente afirmado tanto en las publicaciones y centros de referencia como en la absurda dependencia de los estudios del área en las partes "periféricas" del planeta, entre las cuales nos podemos contar ${ }^{42}$. No son, claramente, una base teórica elaborada desde las luchas y reflexiones latinoamericanas. Por eso es tan importante la creación de "teorías y metodologías propias"43.

Sigue siendo muy interesante e importante - aunque llamativamente ignorada - la crítica y la propuesta realizada, hace unos años ya, por Amado Luiz Cervo. Aunque él plantea una propuesta desde Brasil, da lugar en su texto, expresamente, a pensarla regionalmente, lo cual, a mi entender, la beneficia en coherencia y riqueza. Él entiende que partir de teorías ajenas es peligroso porque son configuradas con intereses determinados de grupos desde una posición dominante. Así su utilización y, más todavía, su aplicación, pueden acentuar la dependencia cultural y la explotación de nuestros pueblos. Para evitarlo exhorta a una lectura crítica y sostiene que existe:

"Estas consideraciones comprueban la necesidad que tiene cada país de destilar las teorías ajenas y de emprender construcciones teóricas que sean epistemológicamente adecuadas y socialmente útiles. América Latina dispone de ellas" 44 .

Propone, además, un interesante camino metodológico para esta construcción de conocimiento, y sostiene que:

"Un conjunto de conceptos, cuando son entrelazados por la función de dotar de comprensión a un determinado objeto de estudio en el área de las ciencias humanas, conduce, en nuestro entender, a la teoría"45.

Este es un momento clave para esas construcciones, porque la avanzada derechista que produjo el empate catastrófico afecta la producción de un pensamiento alternativo sobre la integración que corre el riesgo de sufrir estancamientos y retrocesos inducidos en pro de

${ }^{41}$ BLANEY, David y INAYATULLAH, Naeem, "International Relations from Below" en REUS-SMIT, Christian y SNIDAL, Duncan (eds.), The Oxford handbook of international relations. Oxford University Press, Oxford, pp. 663-675.

42 TICKNER, Arlene B., "Core, periphery and (neo)imperialist International Relations" en European Journal of International Relations, Vol. 19, n० 3, 2013, pp. 627-646.

${ }^{43}$ SOTO ACOSTA, Willy y MORALES CAMACHO, María Fernanda, "Tendencias de investigación en Ciencias Sociales en América Latina" en SOTO ACOSTA, W. (ed.), Ciencias Sociales y..., op.cit., p. 37.

${ }^{44}$ CERVO, Amado Luiz. "Política exterior e relações internacionais do Brasil: enfoque paradigmático" en Revista Brasileira de Política Internacional, Vol. 46, no 2, UnB, Brasilia, 2003, pp. 5-6. La traducción es mía. El texto original en portugués dice así: "Essas considerações comprovam a necessidade que tem cada país de destilar teorias alheias e de partir para construções teóricas que sejam epistemologicamente adequadas e socialmente úteis. A América Latina delas dispõe".

45 CERVO, Amado Luiz, Inserção Internacional: Formação dos conceitos brasileiros, Saraiva, Sao Paulo, 2008 , p. 1. La traducción es mía. El texto original en portugués dice así: "Um conjunto de conceitos, quando entrelaçados pela função de dar compreensão a determinado objeto de estudo na área das ciências humanas, conduz, em nosso entender, à teoria". 
su "normalización".

Es clave también la creación y el fortalecimiento de espacios para esta articulación popular contrahegemónica. Heriberto Cairo Cairou habla de "contraespacios", colocando como ejemplo los movimientos indígenas y su articulación con los teóricos de la colonialidad en América Latina ${ }^{46}$. Esos espacios existentes y sus posibilidades de construcción son innumerables. Pero nombro algunos por si puede servir para reflexión.

Un lugar privilegiado de esta construcción son las regiones de frontera, que hay que apuntar a consolidar como espacios de encuentro y articulación de los movimientos populares. Así pensadas y organizadas, tendrían un papel de "abrir puertas" concretas a esta unión en relación a favorecer articulaciones más amplias a las propias regiones fronterizas. Uno de los elementos es retomar elementos de la praxis de los pueblos de frontera y ayudar a potenciarlos, esto desde la articulación práctica de los movimientos como desde las redes institucionales que favorezcan esta dinámica. Aquí la dimensión contrahegemónica y transestatal se hace evidente, porque la fuerza del estado está puesta, en los ambientes de frontera, fundamentalmente para separar e incomunicar a los pueblos.

Para los países que no son potencias, la articulación de propuestas en el marco de algunos foros internacionales es un elemento que puede tener peso en espacios que pueden volverse favorables ${ }^{47}$. También para los movimientos populares, sobre todo en la medida de que esos foros tengan rasgos democráticos. Aquí hay una tensión entre la creación de espacios autónomos - tanto en lo epistémico como en lo político- y el posible aprovechamiento de espacios más institucionalizados que tienen otros límites, pero, a veces, otras potencialidades. Como esto es parte de la lucha social, tiene sus mismas características fronterizas entre lo institucional y lo "extrainstitucional". Ambos tipos de espacios tienen que ser considerados y evaluados a la hora de poner el foco en su construcción y/o participación.

Otro de estos espacios es la consolidación y construcción de comunidades epistémicas descolonizadas y descolonizadoras. Aquí es importante la revisión del papel de los intelectuales. La visión de Gramsci en este punto puede ser un aporte muy interesante:

"Gramsci consideró que la política no era una lucha por el poder del estado sino una característica central de la existencia humana, ligada a cuestiones de ética y moral. La transformación revolucionaria del capitalismo no determinaría el fin de la política; por primera vez en la historia extendería el Reino de la política a los nuevos sitios (incluyendo el lugar de trabajo) y a todos los temas. Por la misma razón, Gramsci sostuvo que todas las personas son intelectuales en capacidad, aunque no funcionen como tales. Creía que el liderazgo contrahegemónico emana de intelectuales cuyos lazos orgánicos con los grupos subalternos les permiten lograr una unidad de teoría y práctica y de pensamiento y sentimiento, mediando entre lo abstracto y lo concreto de una manera distinta a las élites escolásticas,

${ }^{46}$ CAIRO CAIROU, Heriberto, "La colonialidad y la imperialidad en el sistema-mundo" en Viento Sur, nº 100, enero, 2009, p. 69.

47 ANZELINI, Luciano, "'Autonomía heterodoxa' y Seguridad Internacional: apuntes estratégicos para el caso argentino", en Voces en el Fénix, Vol. 6, no 48, 2015, septiembre, Buenos Aires, p. 118. 
eclesiásticas y políticas tradicionales. Para Gramsci, el papel del intelectual es el de organizador y facilitador: en lugar de llevar la conciencia correcta a las masas 'desde fuera', el intelectual orgánico facilita el movimiento práctico de 'buen sentido' (que los subordinados resistentes ya poseen) a una conciencia más amplia, contrahegemónica, que es sensible a las condiciones específicas de una formación social en una coyuntura dada"48.

\section{4. Ñandereko latinoamericano: construcción de identidades de resistencia y liberación}

Por eso es importante resaltar la importancia de la consolidación y la construcción de identidades contrastivas frente a la dominación y explotación de nuestra región y nuestros pueblos. En esta línea, con absoluto respeto y con la intención de hacer un humilde reconocimiento a la sabiduría de nuestros pueblos originarios, me animo a proponer una comparación con el principio cosmovisional guaraní del ñandereko, relacionándolo con la perspectiva contrahegemónica de la integración latinoamericana.

Una traducción tentativa de este principio que podría hacerse es "nuestro modo propio de convivir": reko - al igual que teko- es "vida". Pero la vida en la cosmovisión guaraní implica un pensamiento comunitario que la concibe siempre unida a los demás miembros de la comunidad, a los antiguos, los ancestros y a la naturaleza. Todo eso configura una convivencia sagrada e inseparable. Por eso, entiendo que es mejor hablar de "convivir". Este principio cosmovisional es, entonces, una afirmación de la identidad comunitaria (humana y con la naturaleza) $)^{49}$.

Este ñandereko es algo ancestral, algo que viene desde antiguo, desde los tiempos anteriores, viene de ymaguare. Así, con ese modo propio, vivieron los padres y abuelos, y legaron ese modo propio de vida en el que ellos están presentes ${ }^{50}$. Dieron su vida viviendo así, para que sus hijos vivan así. Por eso no se puede abandonar el ñandereko, que sería como dejar de hacer presentes a los padres, a los abuelos, a los antiguos. Este principio se debe vivir para que ellos sigan viviendo en la actualización constante de ese modo de vida propio. Pero también hace referencia a los tiempos originarios, hace referencia a la aparición

${ }^{48}$ CARROL, William K. y RATNER, R. S., "Between...", op.cit., p. 12. La traducción es mía. El texto original en inglés dice así: "Gramsci viewed politics not as a struggle for state power but as a central feature of human existence, bound up with issues of ethics and morals. The revolutionary transformation of capitalism would not spell the end or politics; it would for the first time in history extend the realm of politics to new sites (including the workplace) and to all subjects. By the same token, Gramsci held that all people are intellectuals in capacity, if not function. He believed that counter-hegemonic leadership emanates from intellectuals whose organic ties to subaltern groups enable them to achieve a unity of theory and practice and of thinking and feeling, thus mediating between the abstract and concrete in a manner foreign to traditional scholastic, ecclesiastic, and political elites. For Gramsci, the role of the intelectual is that of organizer and facilitator: instead of bringing correct consciousness to the masses 'from without', the organic intelectual facilitates the practical movement from 'good sense' (which resistant subordinates already possess) to a broader, counter-hegemonic consciousness that is sensitive to the specific conditions of a social formation at a given conjuncture".

49 Para el sentido sagrado de la naturaleza y del sentido de comunión con ella puede verse: RAMOS, Lorenzo; RAMOS, Benito y MARTÍNEZ, Antonio, El canto resplandeciente: Ayvu rendy vera, Del Sol, Buenos Aires, 2006. Sobre el impacto que produce la destrucción ecológica en el pueblo guaraní por este sentido de comunión: GRÜNBERG, Friedl Paz, Reflexões sobre a situação dos guarani no Mato Grosso do Sul, Brasil, 2002: guarani. roguata.com/sites/default/.../gruenberg-reflexoes-2002.pdf [Consultado el 16 de marzo de 2018]

50 MELIÁ, Bartomeu, "El 'modo de ser' guaraní en la primera documentación jesuítica" en Revista de Antropología, Vol. 24, 1981, pp. 11-12; CHAMORRO, Graciela, "Imagens espaciais utópicas. Símbolos de liberdade e desterro nos povos guarani" en Indiana, no 27, Ibero-Amerikanisches Institut Preubischer Kulturbesitz, Berlín, 2010, pp. 92-93. 
de la vida, de la comunidad. Tiene una dimensión sagrada que ha sido transmitida como un encargo de cuidar la vida en comunidad. Sin embargo, este modo propio, es dinámico. Es el aprendizaje continuo mientras se camina hacia el Yvy marae'i, hacia la "Tierra sin males"

Este modo propio de ser es entendido, entonces, como un modo bueno, agradable de vivir, lindo, del que uno se enamora, es teko porã, una vida linda, que vale la pena vivir. Es valioso convivir así. Es hermoso. El ñandereko es teko porã. Este otro principio cosmovisional -íntimamente unido al anterior - es muy cercano en su significado a los principios andinos del Sumak Kawsay y del Suma Qamaña, que son habitualmente traducidos como "buen vivir" o "vivir bien"52.

El hecho de ser modo propio le da -como quizás toda identidad, pero esto es especialmente remarcado en la cosmovisión guaraní- una característica de diferencia, de contraste, hasta puede ser de oposición. Marca una identidad contrastiva. Y es muy probable que este sentido contrastivo, este sentido de identidad contrastiva se haya agudizado radicalmente con la experiencia de la invasión europea y la situación colonial. Es posible que se haya profundizado frente al intento de imposición de un otro modo. La experiencia colonial significa el intento de imponer una "vida mala" frente al teko porâ que los guaranís son capaces de vivir. Es querer borrar el ñandereko ${ }^{53}$.

Esta descripción, hecha con afecto y admiración de estos principios cosmovisionales guaranís, es para proponer la consolidación y la construcción continua de un ñandereko latinoamericano. De unas identidades firmes y fuertes, profundamente comunitarias y biocéntricas, capaces de resistir orgullosamente a la imposición colonial, unas identidades enamoradas del modo propio, el de las tradiciones populares dinámicas y construidas constantemente en el caminar histórico, en la lucha por criar la vida en solidaridad con los otros que también luchan. Identidades que continúen la entrega de vida de todos los que lucharon y dieron su vida antes que nosotros. Identidades de resistencia para vivir la lucha contrahegemónica desde una afirmación orgullosa y enamorada de lo popular, de lo propio. Abierto y solidario a lo propio del que lucha en igual forma y claramente opuestos al modo hegemónico, imperialista que se nos quiere imponer. Por eso entiendo que puede pensarse la integración contrahegemónica regional y la construcción de conocimiento que la acompaña así, como un ñandereko latinoamericano.

Para el camino a realizar en la integración latinoamericana y caribeña, inspirados en este principio cosmovisional, podrían quedar estas tareas: primera, la consolidación, crecimiento y radicalización de una identidad latinoamericano-caribeña fuertemente centrada

${ }^{51}$ CHAMORRO, Graciela, Teología guaraní, Abya Yala, Quito, 2004, pp. 176-186. Sobre este principio cosmovisional hay una interesante literatura que revela su sentido espiritual y a la vez socioeconómico. Se puede ver al respecto: CHAMORRO, Graciela. "Imagens espaciais...", op.cit.

52 BENITES, Tonico, Rojeroky hina ha roike jevy tekohape (Rezando e lutando): o movimento histórico dos Aty Guasu dos Ava Kaiowa e dos Ava Guarani pela recuperação de seus tekoha. Tesis de Doctorado presentada en el Programa de Posgraduación en Antropología Social del Museo Nacional - Universidade Federal do Rio de Janeiro, Rio de Janeiro, 2014, p. 245.249; MASO, Tchenna Fernandes. Resistencia Guarani e Kaiowá e a integração latino-americana: reflexões desde a Aty Guasu. Disertación de Maestría presentada en el Programa de Posgraduación en Integración Contemporánea de América Latina en la Universidad Federal de la Integración Latinoamericana. Foz de Iguazú, 2016, p. 143.

${ }^{53}$ MELIÁ, Bartomeu, "El 'modo de ser'...", op.cit., pp. 5-7. 
en un modo propio que se inspira continuamente en la praxis de lucha de nuestros pueblos, praxis con la que se conformó y se cuidó la vida -comunitariamente entendida con los hombres y la naturaleza- desde tiempos ancestrales hasta la actualidad; en segundo lugar, el fortalecimiento de esta identidad -fundamentalmente constructiva - implica también nuclearmente el de su dimensión de resistencia, contrahegemónica, enfrentando el gran obstáculo para la integración que ha sido y es el hecho colonial cuyo protagonista central actual es el poder capitalista norteamericano; tercero, profundizar en la claridad de que la integración latinoamericana no puede asentarse en los criterios capitalistas, sino en criterios comunitarios e igualitarios que nos hermanen como pueblos y que nos ayudan a vivenciar y fortalecer nuestra comunión con la naturaleza; cuarto, repensar biocéntricamente nuestros proyectos económicos de manera que superemos una mirada eurocéntrica de la modernidad y del desarrollo para lo cual es central la propuesta politizada del "buen vivir" en diálogo con todos los planteos de superación del capitalismo con raíces latinoamericanas; en quinto lugar, conjugar continuamente en todas nuestras propuestas el enraizamiento de nuestras tradiciones populares de lucha por la vida con el dinamismo y la creatividad en las respuestas a los nuevos desafíos que nos va presentando la realidad contemporánea, como pueblos caminantes en busca de una tierra sin males para nuestra región, gestando conocimiento y proyectos políticos originales, tanto en su ligazón con la sabiduría de los pueblos originarios como en su heroica capacidad creativa.

\section{Consideraciones finales}

Retomo aquí entonces algunos puntos clave para la consolidación y el crecimiento de una identidad de resistencia basada en la praxis popular de lucha por la vida, la justicia y en la articulación de esas luchas como integración latinoamericana desde abajo, desde el corazón de las mayorías populares. Reafirmo su carácter profundamente político y ético, y la inseparable dimensión epistémica que contienen.

Desde allí, como lugar epistémico-político es posible construir originalmente, como creación heroica, sin copiar ni calcar, otro planteo para pensar la integración, la identidad, las llamadas "relaciones internacionales", y además es posible hacerlo contrahegemónicamente, como un ñandereko latinoamericano que nos afirme en lo que somos y en lo queremos ser, en lucha contra las imposiciones imperialistas.

Es fundamental aquí reafirmar tres grandes "fuentes" para abrevar la construcción, tanto las construcciones políticas como las de conocimiento. La primera son las sabidurías de la praxis de las luchas de las mayorías populares, destacando el lugar nuclear que aquí tienen las sabidurías indígenas, su inmensa capacidad de resistencia -incluso en las peores condiciones y por tantos años - demuestra su potencialidad descolonizadora y revolucionaria. La segunda es la reflexión sobre nuestra historia, pero hecha desde la perspectiva de esas mayorías; esa historia releída desde los que, en general, no escribieron la historia de los manuales. El conocimiento y la reflexión profundos de nuestra historia "desde abajo" es indispensable para tener capacidad de creación y construcción de alternativas políticas y epistémicas de resistencia y contrahegemonía. La tercera son una inmensa cantidad de autores latinoamericanos originales. No son solo los que tienen partida de nacimiento en nuestra región; son los que se inspiraron en esas dos primeras fuentes y construyeron desde allí, pero por eso mismo, en la inmensa mayoría de los casos, fueron marginados e invisibilizados. Nos 
corresponde redescubrirlos y construir en el camino que ellos - aún con mezclas, dificultades y límites - han construido. Mariátegui es, emblemáticamente, uno de ellos.

\section{Bibliografía}

ANZELINI, Luciano, "'Autonomía heterodoxa' y Seguridad Internacional: apuntes estratégicos para el caso argentino" en Voces en el Fénix, Vol. 6, no 48, septiembre, Buenos Aires, 2015.

BENITES, Tonico, Rojeroky hina ha roike jevy tekohape (Rezando e lutando): o movimento histórico dos Aty Guasu dos Ava Kaiowa e dos Ava Guarani pela recuperação de seus tekoha. Tesis de Doctorado presentada en el Programa de Posgraduación en Antropología Social del Museo Nacional - Universidade Federal do Rio de Janeiro, Rio de Janeiro, 2014.

BETHELL, Leslie (ed.), Historia de América Latina. 1. América Latina colonial: la América Precolombina y la Conquista, Crítica, Barcelona, 1990.

BIELER, Andreas y MORTON, Adam David, "A critical theory route to hegemony, world order and historical change: neo-Gramscian perspectives in International Relations", en Capital \& Class, Vol. 28, no 1, marzo, 2004.

BLANEY, David y INAYATULLAH, Naeem, "International Relations from Below" en REUS-SMIT, Christian y SNIDAL, Duncan (eds.), The Oxford handbook of international relations, Oxford University Press, Oxford, pp. 663-675.

BORÓN, Atilio, "Hegemonía e imperialismo en el sistema internacional" en CHOMSKY, Noam et al. (ed.), Nueva Hegemonía Mundial. Alternativas de cambio y movimientos sociales, CLACSO, Buenos Aires, 2004.

BOUCHARD, Jean-François y GUINEA, Mercedes (eds.), Relaciones interculturales en el área ecuatorial del Pacífico durante la época precolombina, BAR International, Oxford, 1989.

BRICEÑO RUIZ, José, "Autonomía: genealogía y desarrollo de un concepto. Su relación con el regionalismo en América Latina" en Cuadernos sobre Relaciones Internacionales, Regionalismo y Desarrollo, Vol. 9, no 18, julio-diciembre, 2014.

BURAWOY, Michael, "Sociological Marxism: The Complementary Convergence of Antonio Gramsci and Karl Polanyi" en Politics \& Society, Vol. 31, n² 2, 2003.

CAIRO CAIROU, Heriberto, "La colonialidad y la imperialidad en el sistema-mundo" en Viento Sur, no 100, enero, 2009.

CAIRO CAIROU, Heriberto y BRINGEL, Breno, "Articulaciones del Sur Global: afinidad cultural, internacionalismo solidario e Iberoamérica en la globalización contrahegemónica" en Geopolítica(s), Vol. 1, no 1, 2010.

CARROLL, William K. y RATNER, R. S., "Between Leninism and Radical Pluralism: Gramscian Reflections on Counter-Hegemony and the New Social Movements" en Critical Sociology, Vol. 20, no 3, 1994.

CERVO, Amado Luiz, Inserção Internacional: Formação dos conceitos brasileiros. Saraiva, Sao Paulo, 2008.

CERVO, Amado Luiz, "Política exterior e relações internacionais do Brasil: enfoque paradigmático" en Revista Brasileira de Política Internacional, Vol. 46, no 2, UnB, Brasilia, 2003.

CHAMORRO, Graciela, "Imagens espaciais utópicas. Símbolos de liberdade e desterro nos povos guarani" en Indiana, no 27, Ibero-Amerikanisches Institut Preubischer Kulturbesitz, Berlín, 2010.

CHAMORRO, Graciela, Teología guaraní, Abya Yala, Quito. 2004.

DE LA TORRE, Verónica, "La acción colectiva transnacional en las teorías de los movimientos sociales y de las Relaciones Internacionales" en CONfines, Vol. 7, nº 14, agosto-diciembre, 2011.

DÍAZ MARTÍNEZ, Karla, "Diplomacia de los Pueblos, propuesta contrahegemónica en las Relaciones Internacionales" en Revista Búsquedas Políticas, Vol. 2, no 1, Universidad Alberto Hurtado, 2013.

ELLACURÍA, Ignacio, "Los pobres, lugar teológico en América Latina", en Archivo Chile, CEME, Santiago de Chile.

FLORES GALINDO, Alberto, Obras completas. T. V. Sur, Lima, 2008.

GAMBINA, Julio C., Los cambios en el sistema mundial y el lugar de América Latina en la lucha por el socialismo en Seminario "Rosa Luxemburg, pensamiento y acción por el socialismo. América Latina en el siglo XXI", FISyP, Buenos Aires, octubre 2005: http://www.rosa-luxemburg-club. de/fileadmin/rls_uploads/pdfs/Themen/Ausland/Seminario_RL.pdf [Consultado el 16 de marzo de 2018]

GAMBINA, Julio C.; RAJLAND, Beatriz y CAMPIONE, Daniel, ¿Hacia dónde va la integración regional de Nuestra América? Un balance necesario, FISyP, Montevideo, 2014.

GARCÍA LINERA, Álvaro, "Empate catastrófico y punto de bifurcación" en Crítica y emancipación. Revista latinoamericana de Ciencias Sociales, Vol. 1, no 1, CLACSO, Buenos Aires, pp. 23-33. 
GERMANÁ, César, El "Socialismo Indo-Americano" de José Carlos Mariátegui: Proyecto de reconstitución del sentido histórico de la sociedad peruana, Amauta, Lima, 1995.

GRÜNBERG, Friedl Paz, Reflexões sobre a situação dos guarani no Mato Grosso do Sul, Brasil, 2002: guarani.roguata.com/sites/default/.../gruenberg-reflexoes-2002.pdf [Consultado el 16 de marzo de 2018]

IBARRA ROJAS, Eugenia y SALGADO GONZÁLEZ, Silvia, "Áreas culturales o regiones históricas en la explicación de relaciones sociales de pueblos indígenas de Nicaragua y Costa Rica de los siglos XV y XVI" en Anuario de Estudios Centroamericanos, no 35-36, Universidad de Costa Rica, 2010.

KNAUFT, Bruce M., "Provincializing America. Imperialism, Capitalism, and Counterhegemony in the Twenty-first Century" en Current Anthropology, Vol. 48, nº 6, diciembre, 2007.

KUSCH, Rodolfo, Esbozo de una Antropología Filosófica Americana, Castañeda, Buenos Aires, 1978.

MARIÁTEGUI, José Carlos, Invitación a la vida heroica, Fondo Editorial del Congreso del Perú, Lima, 2005.

MASO, Tchenna Fernandes, Resistencia Guarani e Kaiowá e a integração latino-americana: reflexões desde a Aty Guasu, Disertación de Maestría presentada en el Programa de Posgraduación en Integración Contemporánea de América Latina en la Universidad Federal de la Integración Latinoamericana. Foz de Iguazú, 2016.

McPHERSON, Alan, "Myths of Anti-Americanism. The Case of Latin America" en The Brown Journal of World Affairs, Vol. 10, no 2, invierno/primavera, 2004.

MELIÁ, Bartomeu, "El 'modo de ser' guaraní en la primera documentación jesuítica (1594-1639)" en Revista de Antropología, Vol. 24, 1981.

PORTANTIERO, Juan Carlos, Clases dominantes y crisis política en la Argentina actual, BVU, Buenos Aires, 2013.

PUIG, Juan Carlos, "Derecho internacional americano, nacionalismo latinoamericano y régimen internacional" en Mundo Nuevo. Revista de Estudios Latinoamericanos, no 1, Instituto de Altos Estudios de América Latina / Universidad Simón Bolívar, Caracas, julio-septiembre, 1978.

QUIJANO, Aníbal, "Estado-nación y 'movimientos indígenas' en la región Andina: cuestiones abiertas" en OSAL, Vol. 6, no 19, CLACSO, Buenos Aires, julio, 2006.

RAJLAND, Beatriz, La estrategia imperialista hoy. Aspectos políticos de la integración en la actualidad y el papel de los Estados Unidos en su relación con América Latina en Seminario "Rosa Luxemburg, pensamiento y acción por el socialismo. América Latina en el siglo XXI", FISyP, Buenos Aires, octubre 2005: http://www.rosa-luxemburg-club.de/fileadmin/rls_uploads/pdfs/Themen/ Ausland/Seminario_RL.pdf [Consultado el 16 de marzo de 2018]

RAMOS, Lorenzo; RAMOS, Benito y MARTÍNEZ, Antonio, El canto resplandeciente: Ayvu rendy vera, Del Sol, Buenos Aires, 2006.

RUSSEL, Roberto y TOKATLIAN, Juan Gabriel, "De la autonomía antagónica a la autonomía relacional: una mirada teórica desde el Cono Sur" en Perfiles latinoamericanos, no 21, diciembre, 2002.

SERBIN, Andrés, "Regionalismo y soberanía nacional en América Latina: los nuevos desafíos" en Documentos CRIES, no 15, Nueva Sociedad / CRIES, Buenos Aires, 2010.

SOTO ACOSTA, Willy, "Introducción", en SOTO ACOSTA, W. (ed.), Ciencias Sociales y Relaciones Internacionales: nuevas perspectivas desde América Latina, Escuela de Relaciones Internacionales de la Universidad Nacional / CLACSO, Heredia, 2015.

SOTO ACOSTA, Willy y MORALES CAMACHO, María Fernanda, "Tendencias de investigación en Ciencias Sociales en América Latina" en SOTO ACOSTA, W. (ed.), Ciencias Sociales y Relaciones Internacionales: nuevas perspectivas desde América Latina, Escuela de Relaciones Internacionales de la Universidad Nacional / CLACSO, Heredia, 2015.

STÉDILE, João Pedro; PIÑERO, Joaquín y BERTOLDI, Manuel, "La integración desde los pueblos" en LEÓN, Irene (coord.), La ALBA: el horizonte latinoamericano del Siglo XXI, FEDAEPS / ALAI, Quito, 2014.

TICKNER, Arlene B., "Core, periphery and (neo)imperialist International Relations" en European Journal of International Relations, Vol. 19, no 3, 2013, pp. 627-646.

TICKNER, Arlene B.; CEPEDA M., Carolina y BERNAL, José Luis, "Anti-Americanismo, Pro-Americanismo y sentido común en América Latina" en Foro Internacional, Vol. 55, nº 3, 2015. 


\section{RELACIONES INTERNACIONALES}

Revista académica cuatrimestral de publicación electrónica Grupo de Estudios de Relaciones Internacionales (GERI) Universidad Autónoma de Madrid, España

www.relacionesinternacionales.info

ISSN 1699 - 3950

ff facebook.com/RelacionesInternacionales

twitter.com/RRInternacional 